\title{
Does basic life support training simplification foster retention of life saving maneuvers?
}

BY PASCAL CASSAN, JOSEPHINE ESCUTNAIRE, JACQUES MANSOURATI, EVGENIYA BABYKINA, DANIEL MEYRAN, ETIENNE ALIOT, CELINE DOS SANTOS, HERVE HUBERT

\section{Abstract}

Objectives. Simplification of Basic Life Support was proposed with the introduction of Chest-Compression only Cardio-Pulmonary Resuscitation (CC-CPR) as an alternative to Standard CPR (S-CPR). This study aimed to compare retention of knowledge, in the general public, of both CPR techniques (CC-CPR vs. S-CPR).

Design, setting and participants. Multicentric prospective comparative cohort study. A training program was conducted among 906 individuals who were assigned to CC-CPR or to S-CPR group. They were evaluated before training (To), after training (T1) and six months later (T2) on 17 CPR assessment criteria, they were evaluated twice at each time period and one global CPR performance score.

Results. Initial knowledge was low. At T1, all CPR performance criteria improved significantly. Results were similar in both groups except for the rate of trainees calling for help and the time to turn on the automated 
external defibrillator and to deliver the first shock. At T2, the knowledge level was lower than at T1. Finally, CPR performance score was lower in both groups at $\mathrm{T} 2$ compared to T1 but statistically higher than at To. CPR performance score was higher in the CC-CPR group than in the S-CPR group at $\mathrm{T} 2(\mathrm{p}=0.041)$.

Conclusions. Performance score was significantly higher in the CC-CPR group. CC-CPR training seems to result in better retention and a faster reaction in the setting of an out of hospital cardiac arrest. Moreover, the retention of knowledge among a trained population fades partially with time. Regular CPR training should therefore be proposed to avoid the loss of benefit with time.

Key words: cardio-pulmonary resuscitation, basic life support, chest compression, mouth-to-mouth ventilation, training, retention

\section{Introduction}

Early Cardio-Pulmonary Resuscitation (CPR), initiated by a bystander, is essential to improve survival in out-of-hospital cardiac arrests (OHCA). $(\underline{1}, 2)$ CPR training courses for the lay public are conducted all around the world to improve rates of survival. However, several studies indicated that a reluctance to perform mouth-to-mouth discouraged the lay public from performing CPR. $(3,4)$ Chest-Compression only Cardio-pulmonary resuscitation (CC-CPR) has been proposed the in 2005 ILCOR Guidelines, and reaffirmed by the 2010 Guidelines, as an alternative to standard cardiopulmonary resuscitation (S-CPR) with ventilation. (5-14) Since 2008, the American Heart Association Emergency Cardiovascular Care Committee approved CC-CPR in circumstances where bystanders are not willing to perform standard CPR. (15) Only a few studies (16-18) have been conducted to evaluate the impact of Basic Life Support (BLS) training on the ability of bystanders to retain what they learnt at S-CPR or CC-CPR trainings. Moreover, the relative effectiveness of the two techniques on long-term survival has been controversial. Recent publications showed a better outcome in OHCA patients with CC-CPR 
over conventional CPR. $(\underline{19}, \underline{20})$

The aim of this study was to compare knowledge retention of CC-CPR trained subjects with S-CPR trained subjects by comparing their CPR performance according to the CPR Performance Evaluation Score (CPRPES) after a six month period.

\section{Materials and methods}

\section{Study design}

This multicentric prospective comparative cohort study was conducted in 5 French cities (Brest, Lyon, Montpellier, Nancy and Paris): volunteers of the French Federation of Cardiology (FFC) who participated in a CPR training program were included. Individuals were initially separated into 2 groups, according to the type of CPR training to be provided (CC-CPR or S-CPR).

The CC-CPR training program is a progressive and practical training session during which the necessary knowledge to adequately respond to a situation is demonstrated through practical exercises. The 40 to 45 minutes initiation session uses interactive teaching techniques, described in the French Red Cross' educational standards approved by the 'Direction générale de la sécurité civile et de la gestion des crises' (DGSCGC - French Ministry of the Interior), and involves participants, leading them to act and adopt the same behaviors as if they were in a real situation. At the start of the session, the trainer presents the following scenario: 'The victim is not moving, not responding, not breathing. You have a cell phone. An automatic external defibrillator (AED) is nearby.' The participant learns how to recognize a victim with no signs of life (not breathing and unconsciousness); to call or to alert emergency services (Call 15 - emergency services Service Aide Médicale Urgente (SAMU)) and immediately ask if an AED is available. Then, the participant learns how to perform chest compressions (hands-only CPR) according to international standards (depth of 5 to $6 \mathrm{~cm}$, made in the center of the 
person's chest, at a frequency between 100 and 120 per minute), to be performed until the use of a defibrillator is available or until emergency services take over. Finally, the participant learns how to use an AED.

The S-CPR training program is based on the CC-CPR to which is added a 5 minute module on how to do mouth-to-mouth. The participant learns to perform standard CPR, which includes mouth-to-mouth resuscitation and chest compressions according to international standards (slow, gradual breaths, two in less than 5 seconds with a ratio chest compressions / ventilations of 30/2). Watch for the person's chest to rise to stop the breaths.

Participants were trained in groups of 10 , thereafter. Instructors were chosen from each Croix Rouge Française (CRF - French Red Cross) local branch. In each city, a coordinator was in charge of harmonization and methodology control. Five instructors were in charge of the one-hour training session and ten instructors were in charge of the evaluation process. CRF instructors are certified by a national training program (First Aid National Instructor Certificate). In each city, the study took place in halls with sufficient room to teach groups of 10 individual attendees but also individual stations for a strict blinded individual assessment.

\section{Interventions}

The training program and evaluation materials were identical in all cities:

- AmbuMan ${ }^{\circledR}$ manikin (Ambu, Denmark) with medium thorax resistance

- Automated external defibrillator (AED) training (AED1o WelchAllyn ${ }^{\circledR}$ trainer or Red Cross AED Trainer) was set to shock ineffective.

The first training session took place in November or December 2010, and the second session in May or June 2011. The three phases of evaluation 
of the individuals participating in the study were as follows:

To: BLS knowledge of participants was evaluated individually (a closed space was reserved for each person) and following a precise scenario: 'You're at the supermarket in (city or place of study). On your arrival a man is unconscious and lying on the ground. Next to him, someone brought a defibrillator and tells you he doesn't know how to use it. A mobile phone is available. Act as in a real situation'. The duration of the simulation was 3 minutes for each attendee. After the first evaluation, participants were trained in groups of 10 thereafter.

T1: Immediately after training, BLS knowledge of participants was evaluated individually following the same scenario as for To.

T2: Six months after initial training, BLS knowledge was evaluated individually following the same scenario as for To. Evaluation took place in order to determine the level of retention of BLS knowledge.

To be included in the final results, each trainee must have been evaluated three times: before training (To), immediately after training (T1) and six months later (T2).

\section{Outcome measures}

Adequate situation assessment, call for help, compressions with the adequate depth and rate, number of compressions with correct hand position - as recommended by European Resuscitation Council (ERC) 2010 Guidelines - plus correct pad placement and the time of the first shock were evaluated.

To avoid artefacts due to predictable differences in evaluation by instructors, a detailed assessment table with 19 criteria- 17 CPR assessment criteria and two intervention time measurements- were assessed.

Our main criteria was the CPR-PES. This score was calculated (table 1) and used by all instructors along with a stopwatch. The CPR-PES was 
designed in order to summarize CPR effectiveness. The criteria used to design the score were discussed with CPR training experts and score elaboration was carried out under medical expertise. It has 3 levels: 'less effective CPR', 'effective CPR 'and 'highly effective CPR'. According to the criteria assessment table (table 1), the score was determined as follows:

1. If at least Q1-1, Q1-3, Q1-4, Q1-5, Q5-1, and Q5-2 were answered 'yes' and Tshock $\leq 180$ seconds, the CPR was considered 'highly effective' in CCCPR group. The Q5-3 criteria (breaths are effective) were also requested in S-CPR group.

2. If Q1-4 and Q1-5 were answered 'yes'and Tshock $\leq 180$ seconds, the CPR was considered 'effective'.

3. If none of these conditions were filled, the CPR was considered 'less effective An information session for the instructors was organized prior to the study by each coordinator to explain how to use the assessment table.

\section{Statistical analysis}

The distribution of all variables was tested using the KolmogorovSmirnov test. The main characteristics of the population were expressed as median [Interquartile Range] or frequency (percentage), as appropriate. Differences between CPR training subgroups were analyzed using the Mann-Whitney test and Chi-square test or Fisher's exact test, as required. The ability to perform CPR correctly over time was evaluated using the Mc Nemar test (for binary qualitative variables) and the Wilcoxon test (for ordinal variables and quantitative variables). All tests were conducted with a two-sided alpha level of 0.05. All statistical analyses were performed using SPSS software, version 19 (IBM Inc., USA).

\section{Results}

906 persons were evaluated. 516 who participated in all sessions had their results analyzed. The initial population was mainly female (61\%; 
553/906). Median age was 62 [39;69] (mean 53.7 \pm 21 years) years. There were no statistical differences in population characteristics (gender, age, previous training) between the two subgroups of trained participants (S$\mathrm{CPR}$ and $\mathrm{CC}-\mathrm{CPR}$ ) and between the different cities. In the initial study population, 55.7\% (505/906) had never received previous training. Six months after the initial evaluation and training, 56.9\% (516/906) of the initial population attended the second round of evaluation. However the population remained homogeneous: S-CPR group $(n=261)$ and CC-CPR group $(\mathrm{n}=255)$. The main characteristics of the participants of the two training groups were similar (table 2).

\section{Initial knowledge (To)}

Initial knowledge of BLS among the 516 individuals who participated in all sessions (To, T1 and T2) was relatively low, except for the concepts of 'call for help' (69.8\%; 360/516) and 'take the available AED' (64.5\%;

333/516). Most of the other elements of knowledge were known by less than $50 \%$ of the population, including a very low level of effectiveness of implemented actions (effectiveness of mouth-to-mouth breaths $=7.3 \%$ (19/261) and CPR-PES=less effective CPR in 91.9\% (422/516) of cases). The median time to turn on the AED and the median time to deliver the first shock were 114 [72;161] (mean 120.9 \pm 63.8 seconds) and 166 [124;206] seconds (mean $168.7 \pm 61.1$ seconds), respectively. The rates of initial knowledge were similar for all assessment criteria in the S-CPR and CC-CPR groups (table 3).

\section{Knowledge immediately after training (T1)}

After training, all assessment criteria showed statistically significant variations indicating an improvement in the level of knowledge and the effectiveness of CPR between To and T1. Checking the reaction of the victim was performed by $90.1 \%(465 / 516)$ of participants and AED was used by $92.2 \%$ (476/516). The mean time to turn on the AED improved by 22 seconds and the mean time to deliver the first shock improved by 
45 seconds. The CPR training program resulted in a significant improvement in technical quality of the main elements of CPR.

Significant variations were noticed when we cross-tabulated variations in the level of knowledge (between To and T1) and participants or training characteristics. For all subgroups, there were approximately four times more participants clearing the airways of the victim. Similarly, almost all participants turned on the AED. Finally, CPR-PES had highly effectively increased by forty.

When comparing the knowledge level between the two training groups (S-CPR and CC-CPR), there were no statistically significant differences except for the criteria 'Check breathing of the victim' $(p=0.033)$ and for the two measured times (time of turning on the AED, $p=0.008$ and time of delivering the first shock, $\mathrm{p}=\mathbf{0 . 0 2 1 )}$ : the results were better for the CCCPR group (table 4).

\section{Knowledge at 6 months (T2)}

At 6 months we recorded a significantly higher level of knowledge for all assessment criteria in comparison with To (table 4). These results were valid for the general population and for the two training groups. However, between T1 and T2 the level of knowledge significantly decreased in most of the assessment criteria. We also recorded longer times in setting up the AED and delivering the first shock. The pads were significantly less often correctly set. For both training groups, we found the same results, except in the S-CPR group, for the times to turn on the AED and to deliver the first shock, for which T2 values dropped back to To values. Finally, we noted that CPR-PES was lower for both training groups between $\mathrm{T} 1$ and $\mathrm{T} 2$, but the values found in $\mathrm{T} 2$ were statistically higher to those of To and there was a statistically significant difference ( $\mathrm{p}=0.041$ ) between the performance score of the S-CPR group and that of CC-CPR group (figure 1, table 4).

\section{Discussion}


Prompt implementation of the 'chain of survival' is the best way to increase the survival odds of a victim of cardiac arrest. Though less than $5 \%$ of cardiac arrest victims survive in France while survival increases up to $30 \%$ in countries where special actions are undertaken to improve the efficacy of the 'chain of survival' in the event of cardiac arrest. (21) This figure of $5 \%$ shows that CPR knowledge among the French population is low. Not surprisingly, in the initial study population, 55.7\% (505/906) had never received previous training. Consequently, initial knowledge of BLS among individuals who participated in all the sessions (To, T1 and T2) was relatively low, except for younger and already trained participants who showed a higher level of initial knowledge. Furthermore, previously trained participants were more effective in analyzing the situation, in performing first aid on victims and in performing CPR. Among trained participants, CPR-PES was also significantly better than for others. All these elements highlight the need for large and regular information campaigns, for example in the media. It also stresses the need for massive training initiatives in the French population to increase the effectiveness of CPR. Training the general public on CPR and increasing the number and the visibility of available AEDs in public places should be a major public health concern as 50,000 annual deaths from OHCA are reported in France. A very high number of lives can potentially be saved if early CPR is performed in cases of OHCA.

We found that all assessment criteria improved in a highly significant way just after CPR training in our study population. However, when comparing the knowledge level between the two training groups (S-CPR and CC-CPR), no statistical difference was found except for the criteria 'Check breathing of the victim' $(\mathrm{p}=0.033)$ and time to turn on the AED, $\mathrm{p}=0.008$ and time of delivering the first shock, $\mathrm{p}=0.021$, where results were better for the CC-CPR group. This result seems logical, as the person performing CC-CPR has less maneuvers to do (he/she does not do mouth-to-mouth breaths). Better memorization leads to a faster reaction and higher efficiency. The time saved when CC-CPR is performed may be one of the reasons for higher survival. $(\underline{19}, \underline{20})$ 
Moreover, at 6 months, although CPR effectiveness score decreased in our population, it remained higher than the initial score. Both effective and highly effective CPR scores were obtained for $26.3 \%$ of the population. Importantly, these scores were significantly more frequently obtained in the CC-CPR subgroup than in the S-CPR subgroup (29.3\% vs. 23.4\%). When we focus on the proportion of individuals with a highly effective CPR score, the difference is also highly significant (10.2\% in the CC-CPR subgroup vs. $6.0 \%$ in the $\mathrm{S}-\mathrm{CPR}$ subgroup; $\mathrm{p}=0.041$ ).

These results show that even though we did not record significantly higher effectiveness of simplified CPR (with chest-compressions only and no mouth-to-mouth breathing) in comparison with standard CPR, criteria by criteria, the retention seems better and the CPR effectiveness is significantly higher.

As we could easily forecast, global knowledge decreases over time and only one third of our study population was still performing CPR effectively 6 months after training. That means that retention fades with time (and quite a short period of time) and that regular training is necessary to prevent loss of knowledge.

\section{Study limitations}

Only $56.9 \%$ of the initial volunteers participated in the evaluation at 6 months. However, this percentage was predictable and finally the two subgroups remained homogenous and representative of the initial subgroups. Therefore, the results obtained in the remaining volunteers were appropriate for analysis. The mean age of the population who participated in the study is higher than the French mean age. Mean age of the study population was $53.7 \pm 21$ years $v s .40 .6$ years in the French population. As the age of the studied population may have a significant impact on the level of CPR maneuvers' retention, this parameter should be taken into account.

\section{Conclusions}


CPR knowledge increased rapidly with a single training session that lasted only 45 minutes ( $\mathrm{T} 1$ compared to To), but the CPR effectiveness score decreased within 6 months of initial training. Nevertheless, it remained higher than the initial score (T1). As the performance score was significantly higher in CC-CPR group when compared to S-CPR group, CC-CPR seemed to result in better retention and a faster reaction in the setting of an OHCA. Moreover, the retention of knowledge in a trained population seemed to fade partially with time, and quite a short period of time. Regular CPR training should therefore be proposed to prevent the loss of benefit with time.

In conclusion, schools, private or public companies or institutions and patient associations should develop simplified CPR training programs to be conducted regularly, over a lifetime, to improve lay public reactions to cardiac arrest and improve survival on a nationwide basis. In complement, information campaigns should also be conducted. A 60 minute-long simplified training session, undertaken several times in a lifetime, in a country that regularly raises awareness of cardiac arrest and $\mathrm{CPR}$ at a national level, are, according to us, the three necessary conditions/elements to significantly increase the survival rates of OHCA.

\section{Key messages}

1. Early CPR initiated by a bystander is essential to improve survival in OHCA

2. BLS simplification is one way to improve cardiopulmonary resuscitation

3. The retention of knowledge in a trained population fades over a short period of time

4. A regular, simplified CPR training program should be proposed

\section{References}

1. Gallagher EJ, Lombardi G, Gennis P. Effectiveness of bystander cardiopulmonary resuscitation and survival following out-of-hospital cardiac arrest. Jama 1995;274(24):1922-5. 
2. Weston CF, Wilson RJ, Jones SD. Predicting survival from out-ofhospital cardiac arrest: a multivariate analysis. Resuscitation 1997;34(1):27-34.

3. Jelinek GA, Gennat H, Celenza T, O’Brien D, Jacobs I, Lynch D. Community attitudes towards performing cardiopulmonary resuscitation in Western Australia. Resuscitation 2001;51(3):239-46.

4. Kuramoto N, Morimoto T, Kubota Y, Maeda Y, Seki S, Takada K, et al. Public perception of and willingness to perform bystander CPR in Japan. Resuscitation 2008;79(3):475-81.

5. Bohm K, Rosenqvist M, Herlitz J, Hollenberg J, Svensson L. Survival is similar after standard treatment and chest compression only in out-ofhospital bystander cardiopulmonary resuscitation. Circulation 2007;116(25):2908-12.

6. Hallstrom A, Cobb L, Johnson E, Copass M. Cardiopulmonary resuscitation by chest compression alone or with mouth-to-mouth ventilation. N Engl J Med 2000;342(21):1546-53.

7. Hazinski MF, Nolan JP, Billi JE, Bottiger BW, Bossaert L, de Caen AR, et al. Part 1: Executive summary: 2010 International Consensus on Cardiopulmonary Resuscitation and Emergency Cardiovascular Care Science With Treatment Recommendations. Circulation 2010;122(16 Suppl 2):S250-75.

8. Iwami T, Kawamura T, Hiraide A, Berg RA, Hayashi Y, Nishiuchi T, et al. Effectiveness of bystander-initiated cardiac-only resuscitation for patients with out-of-hospital cardiac arrest. Circulation 2007;116(25):2900-7.

9. Nolan JP, Soar J, Zideman DA, Biarent D, Bossaert LL, Deakin C, et al. European Resuscitation Council Guidelines for Resuscitation 2010 Section 1. Executive summary. Resuscitation 2010;81(10):1219-76.

10. Olasveengen TM, Wik L, Steen PA. Standard basic life support vs. continuous chest compressions only in out-of-hospital cardiac arrest. 
Acta Anaesthesiol Scand 2008;52(7):914-9.

11. Ong ME, Ng FS, Anushia P, Tham LP, Leong BS, Ong VY, et al. Comparison of chest compression only and standard cardiopulmonary resuscitation for out-of-hospital cardiac arrest in Singapore. Resuscitation 2008;78(2):119-26.

12. SOS-KANTO study group. Cardiopulmonary resuscitation by bystanders with chest compression only (SOS-KANTO): an observational study. Lancet 2007;369(9565):920-6.

13. Waalewijn RA, Tijssen JG, Koster RW. Bystander initiated actions in out-of-hospital cardiopulmonary resuscitation: results from the Amsterdam Resuscitation Study (ARRESUST). Resuscitation 2001;50(3):273-9.

14. Berg RA, Hemphill R, Abella BS, Aufderheide TP, Cave DM, Hazinski MF, et al. Part 5: adult basic life support: 2010 American Heart Association Guidelines for Cardiopulmonary Resuscitation and Emergency Cardiovascular Care. Circulation 2010;122(18 Suppl 3):S685705 .

15. Sayre MR, Berg RA, Cave DM, Page RL, Potts J, White RD. Handsonly (compression-only) cardiopulmonary resuscitation: a call to action for bystander response to adults who experience out-of-hospital sudden cardiac arrest: a science advisory for the public from the American Heart Association Emergency Cardiovascular Care Committee. Circulation 2008;117(16):2162-7.

16. Hill K, Mohan C, Stevenson M, McCluskey D. Objective assessment of cardiopulmonary resuscitation skills of 10-11-year-old schoolchildren using two different external chest compression to ventilation ratios. Resuscitation 2009;80(1):96-9.

17. Nishiyama C, Iwami T, Kawamura T, Ando M, Yonemoto N, Hiraide A, et al. Effectiveness of simplified chest compression-only CPR training for the general public: a randomized controlled trial. Resuscitation 2008;79(1):90-6. 
18. Nishiyama C, Iwami T, Kawamura T, Ando M, Yonemoto N, Hiraide A, et al. Quality of chest compressions during continuous CPR; comparison between chest compression-only CPR and conventional CPR. Resuscitation 2010;81(9):1152-5.

19. Dumas F, Rea TD, Fahrenbruch C, Rosenqvist M, Faxen J, Svensson $\mathrm{L}$, et al. Chest compression alone cardiopulmonary resuscitation is associated with better long-term survival compared with standard cardiopulmonary resuscitation. Circulation 2013;127(4):435-41.

20. Iwami T, Kitamura T, Kawamura T, Mitamura H, Nagao K, Takayama M, et al. Chest compression-only cardiopulmonary resuscitation for out-of-hospital cardiac arrest with public-access defibrillation: a nationwide cohort study. Circulation 2012;126(24):2844-51.

21. Atwood C, Eisenberg MS, Herlitz J, Rea TD. Incidence of EMStreated out-of-hospital cardiac arrest in Europe. Resuscitation 2005;67(1):75-80.

\section{Acknowledgments}

To the French Red Cross (Croix-Rouge française) instructors who conducted the training sessions and evaluations for this study and to the French Federation of Cardiology (Fédération Française de Cardiologie) and its regional and national teams who organized the recruitment and the logistical aspects of the study (printing of documents, data entry...)

Table 1. Assessment criteria.

Q1-1: Check reaction of the victim

Q1-2: Clear the airway of the victim

Q1-3: Check breathing of the victim

Q1-4: Call for help 
Q1-5 Start CPR before requesting AED

Q2-1: Take the available AED

Q2-2: Turn on the AED

Q3-1: At the prompt: expose the person's chest

Q3-2: At the prompt: take the AED pads out of the bag

Q3-3: At the prompt: place the AED pads on the person's chest

Q3-4: At the prompt: don't touch the victim and the AED connectors

Q4-1: At the prompt: Ensure nobody touches the victim and the AED

Q4-2: A shock is needed: adapt behaviour in consequence

Q5-1: At the prompt: start CPR

Q5-2: Chest compressions are effective

Q5-3: Breaths are effective

Q5-4: After the shock: adapt behaviour in consequence

Taed: Time of turn on the AED

Tshock: Time of delivering the first shock

CPR-PES (practical evaluation score)

1. Less effective CPR

2. Effective CPR

3. Highly effective CPR

AED, automated external defibrillator; CPR, cardiopulmonary resuscitation.

Table 2. Description of the population and both subgroups participating in all assessment steps $(\mathrm{n}=516)$. 


$$
\text { Population } \begin{array}{ll}
\mathrm{n}=255 & \mathrm{CC}-\mathrm{CPR} \quad \mathrm{p} \\
\mathrm{n}=261 &
\end{array}
$$

\begin{tabular}{|c|c|c|c|c|}
\hline City & $\begin{array}{l}129 \\
(25.0 \%)\end{array}$ & $\begin{array}{l}63 \\
(24.1 \%)\end{array}$ & $\begin{array}{l}66 \\
(25.9 \%)\end{array}$ & \multirow{6}{*}{$\mathrm{NS}^{\mathrm{a}}$} \\
\hline Brest & $\begin{array}{l}96 \\
(18.6 \%)\end{array}$ & $\begin{array}{l}55 \\
(21.1 \%)\end{array}$ & $\begin{array}{l}41 \\
(16.1 \%)\end{array}$ & \\
\hline Lyon & & $12(50 \%)$ & $11(12 \%)$ & \\
\hline Montpellier & $(4.5 \%)$ & $13(5.070)$ & $11(4.3 \%)$ & \\
\hline Nancy & $\begin{array}{l}150 \\
(29.0 \%)\end{array}$ & $\begin{array}{l}67 \\
(25 \cdot 7 \%)\end{array}$ & $\begin{array}{l}83 \\
(32.5 \%)\end{array}$ & \\
\hline Paris & $\begin{array}{l}117 \\
(22.7 \%)\end{array}$ & $\begin{array}{l}63 \\
(24.1 \%)\end{array}$ & $\begin{array}{l}54 \\
(21.2 \%)\end{array}$ & \\
\hline Gender & 202 & 98 & 104 & \multirow{3}{*}{$\mathrm{NS}$} \\
\hline Male & $(39.170)$ & $(3 / .5 / 0)$ & $(40.0 \% 0)$ & \\
\hline Female & $\begin{array}{l}314 \\
(60.9 \%)\end{array}$ & $\begin{array}{l}163 \\
(62.5 \%)\end{array}$ & $\begin{array}{l}151 \\
(59.2 \%)\end{array}$ & \\
\hline Age (years) & $\begin{array}{l}62 \\
{[39 ; 69]}\end{array}$ & $\begin{array}{l}61 \\
{[31 ; 70]}\end{array}$ & $\begin{array}{l}62 \\
{[45 ; 69]}\end{array}$ & $\mathrm{NS}^{\mathrm{c}}$ \\
\hline Previous training & $\begin{array}{l}235 \\
(45.5 \%)\end{array}$ & $\begin{array}{l}130 \\
(49.8 \%)\end{array}$ & $\begin{array}{l}105 \\
(41.2 \%)\end{array}$ & \multirow{3}{*}{$\mathrm{NS}$} \\
\hline Yes & 281 & & 150 & \\
\hline No & $(54.5 \%)$ & $(50.2 \%)$ & $(58.8 \%)$ & \\
\hline $\begin{array}{l}\text { Type of CPR training } \\
\text { provided }\end{array}$ & $\begin{array}{l}261 \\
(50.6 \%)\end{array}$ & & & \\
\hline S-CPR & 255 & & & \\
\hline CC-CPR & $(49.4 \%)$ & & & \\
\hline
\end{tabular}

CC-CPR, Chest compression only cardiopulmonary resuscitation; S-CPR, Standard cardiopulmonary resuscitation. 
a, Chi-square test; ${ }^{\mathrm{b}}$, Fischer's exact test; ${ }^{\mathrm{c}}$, Mann-Whitney test.

Table 3. Description and comparison of initial knowledge level (To).

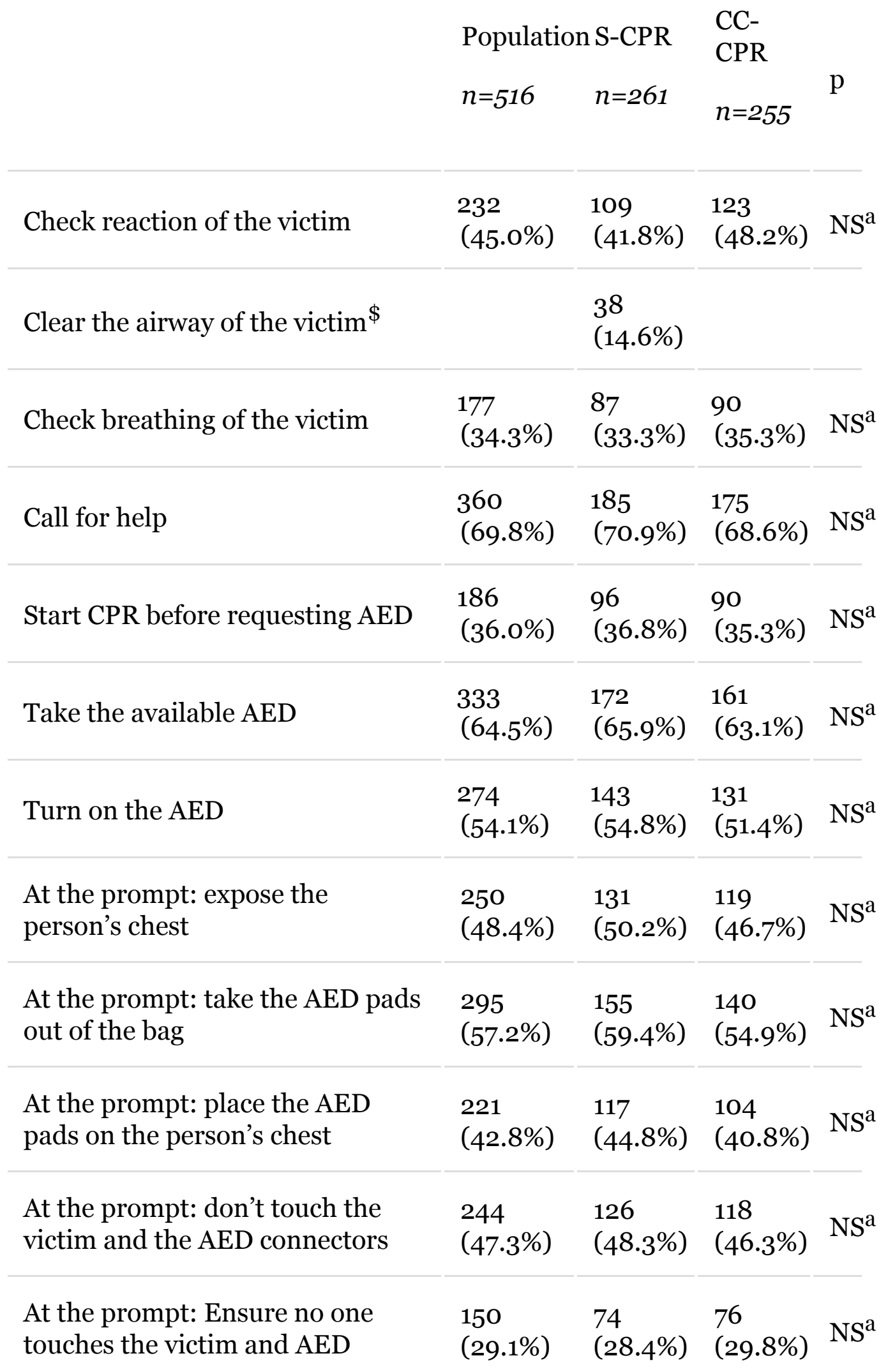




\begin{tabular}{|c|c|c|c|c|}
\hline $\begin{array}{l}\text { A shock is needed: adapt } \\
\text { behaviour in consequence }\end{array}$ & $\begin{array}{l}175 \\
(33.9 \%)\end{array}$ & $\begin{array}{l}94 \\
(36.0 \%)\end{array}$ & $\begin{array}{l}81 \\
(31.8 \%)\end{array}$ & $\mathrm{NS}^{\mathrm{a}}$ \\
\hline At the prompt: start CPR & $\begin{array}{l}100 \\
(19.4 \%)\end{array}$ & $\begin{array}{l}42 \\
(16.1 \%)\end{array}$ & $\begin{array}{l}58 \\
(22.7 \%)\end{array}$ & $\mathrm{NS}^{\mathrm{a}}$ \\
\hline Chest compressions are effective & $\begin{array}{l}74 \\
(14 \cdot 3 \%)\end{array}$ & $\begin{array}{l}36 \\
(13.8 \%)\end{array}$ & $\begin{array}{l}38 \\
(14.9 \%)\end{array}$ & $\mathrm{NS}^{\mathrm{a}}$ \\
\hline Breaths are effective ${ }^{\$}$ & & $\begin{array}{l}19 \\
(7 \cdot 3 \%)\end{array}$ & & \\
\hline $\begin{array}{l}\text { After the shock: adapt behaviour } \\
\text { accordingly }\end{array}$ & $\begin{array}{l}101 \\
(19.6 \%)\end{array}$ & $\begin{array}{l}52 \\
(19.9 \%)\end{array}$ & $\begin{array}{l}49 \\
(19.2 \%)\end{array}$ & $\mathrm{NS}^{\mathrm{a}}$ \\
\hline Time of turning on the AED & $\begin{array}{l}114 \\
{[72 ; 161]}\end{array}$ & $\begin{array}{l}118 \\
{[72 ; 165]}\end{array}$ & $\begin{array}{l}111 \\
{[71 ; 151]}\end{array}$ & $\mathrm{NS}^{\mathrm{c}}$ \\
\hline Time of delivering the first shock & $\begin{array}{l}166 \\
{[124 ; 206]}\end{array}$ & $\begin{array}{l}170 \\
{[128 ; 205}\end{array}$ & $\begin{array}{l}160 \\
][120 ; 215]\end{array}$ & ]$^{\mathrm{NS}^{\mathrm{c}}}$ \\
\hline $\begin{array}{l}\text { CPR-PES (practical evaluation } \\
\text { score) }\end{array}$ & $\begin{array}{l}422 \\
(91.9 \%)\end{array}$ & $\begin{array}{l}218 \\
(91.7 \%)\end{array}$ & $\begin{array}{l}204 \\
(92.3 \%)\end{array}$ & \\
\hline Less effective CPR & $\begin{array}{l}34 \\
(7.4 \%)\end{array}$ & $\begin{array}{l}19 \\
(7.9 \%)\end{array}$ & $\begin{array}{l}15 \\
(6.8 \%)\end{array}$ & $\mathrm{NS}^{\mathrm{b}}$ \\
\hline $\begin{array}{l}\text { Effective CPR } \\
\text { Highly effective CPR }\end{array}$ & $\begin{array}{l}3 \\
(0.7 \%)\end{array}$ & $\begin{array}{l}1 \\
(0.4 \%)\end{array}$ & $\begin{array}{l}2 \\
(0.9 \%\end{array}$ & \\
\hline
\end{tabular}

AED, automated external defibrillator; CPR, cardiopulmonary resuscitation; S-CPR, Standard cardiopulmonary resuscitation; CC-CPR, Chest compression only cardiopulmonary resuscitation.

\$ Only for the group standard cardiopulmonary resuscitation

${ }^{\mathrm{a}}$, Fischer's exact test; ${ }^{\mathrm{b}}$, Chi-square test; ${ }^{\mathrm{c}}$, Mann-Whitney test.

Table 4. Evolution of knowledge level 6 months after training (T2) $(n=516)$. 


$$
\begin{array}{rll}
\mathrm{T}_{2}-\mathrm{To}^{\mathrm{a}} & \mathrm{T} 2- & \mathrm{CPR} \\
& \mathrm{T}^{\mathrm{a}} & v s \\
& & \mathrm{CC}- \\
& & \mathrm{CPR})^{\mathrm{b}}
\end{array}
$$

\begin{tabular}{|c|c|c|c|c|c|c|c|c|}
\hline $\begin{array}{l}\text { Check } \\
\text { reaction of } \\
\text { the victim }\end{array}$ & + & + & + & - & - & $\mathbf{o}$ & NS & NS \\
\hline $\begin{array}{l}\text { Clear the } \\
\text { airway of the } \\
\text { victim }^{\$}\end{array}$ & & + & & & - & & & \\
\hline $\begin{array}{l}\text { Check } \\
\text { breathing of } \\
\text { the victim }\end{array}$ & + & + & + & - & - & - & 0.0 & $\mathrm{NS}$ \\
\hline Call for help & + & + & + & $\mathbf{o}$ & $\mathbf{o}$ & $\mathbf{o}$ & NS & NS \\
\hline $\begin{array}{l}\text { Start CPR } \\
\text { before } \\
\text { requesting } \\
\text { AED }\end{array}$ & + & + & + & $\mathbf{o}$ & $\mathbf{o}$ & $\mathbf{0}$ & NS & NS \\
\hline
\end{tabular}

Population $\begin{array}{cc}\text { S- } & \text { CC- } \\ \text { CPR CPR }\end{array} \quad$ Population $\begin{aligned} & \text { S- } \\ & \text { CPR CPR }\end{aligned}$

Take the

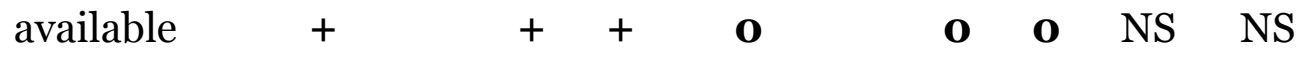
AED

Turn on the AED

$$
+\quad+\quad+\quad-\quad-\quad-\quad \text { NS NS }
$$

At the prompt: expose the $+\quad++-\quad+\quad$ NS NS person's chest

At the prompt: take the AED pads $++\quad+\quad+\quad-\quad \begin{array}{llllll} & \text { o } & \text { o } & \text { NS } & \text { NS }\end{array}$ out of the bag 
At the

prompt:

place the

AED pads $++\quad+\quad+\quad-\quad-$ NS NS

on the

person's

chest

At the

prompt:

don't touch

the victim

$+\quad+\quad-\quad-\quad-\quad$ NS NS

and the AED

connectors

At the

prompt:

Ensure no

one touches

$+\quad+\quad$ o

- 0 NS NS

the victim

and the AED

A shock is

needed:

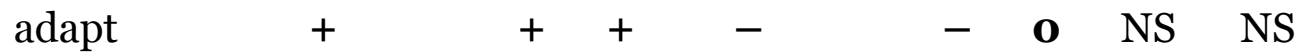

behavior

accordingly

At the

prompt:

start CPR

Chest

compressions $+\quad+\quad+\quad-\quad-\quad-$ NS NS

are effective

Breaths are

effective ${ }^{\$}$

$+$

After the

shock: adapt

behaviour

$+$

$++$

$-\quad-\quad \mathrm{NS}$ NS

accordingly

Time to turn 


\begin{tabular}{|c|c|c|c|c|c|c|c|c|}
\hline on the AED & - & $\mathbf{o}$ & - & + & + & + & \multicolumn{2}{|c|}{$0.008 \mathrm{NS}$} \\
\hline $\begin{array}{l}\text { Time to } \\
\text { deliver the } \\
\text { first shock }\end{array}$ & - & $\mathbf{o}$ & - & + & + & + & 0.021 & NS \\
\hline \multicolumn{9}{|l|}{$\begin{array}{l}\text { CPR-PES } \\
\text { (practical } \\
\text { evaluation } \\
\text { score) }\end{array}$} \\
\hline $\begin{array}{l}\text { Less } \\
\text { effective }\end{array}$ & - & - & - & + & + & + & & \\
\hline CPR & + & + & + & + & + & + & NS & 0.041 \\
\hline $\begin{array}{l}\text { Effective } \\
\text { CPR }\end{array}$ & + & + & + & - & - & - & & \\
\hline $\begin{array}{l}\text { Highly } \\
\text { effective } \\
\text { CPR }\end{array}$ & & & & & & & & \\
\hline
\end{tabular}

AED, automated external defibrillator; CC-CPR, Chest compression only cardiopulmonary resuscitation; CPR, cardiopulmonary resuscitation; SCPR, Standard cardiopulmonary resuscitation.

+ statistically significant increase; - statistically significant decrease; o no statistically significant difference.

\$ Only for the group standard cardiopulmonary resuscitation; ${ }^{\mathrm{a}}, \mathrm{Mc}$ Nemar test for binary variables, Wilcoxon test for the two time variables, Wilcoxon test for CPR-PES; b, Fischer exact test for binary variables, Mann-Whitney for the two time variables, Chi-square test for CPR-PES.

Figure 1. Comparison of practical evaluation score (CPR-PES) at To, T1 and T2.

Less effective CPR by group

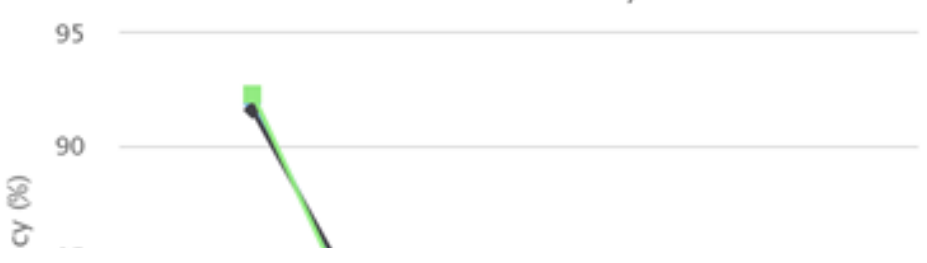


SIGNA VITAE 2016; 11(1):

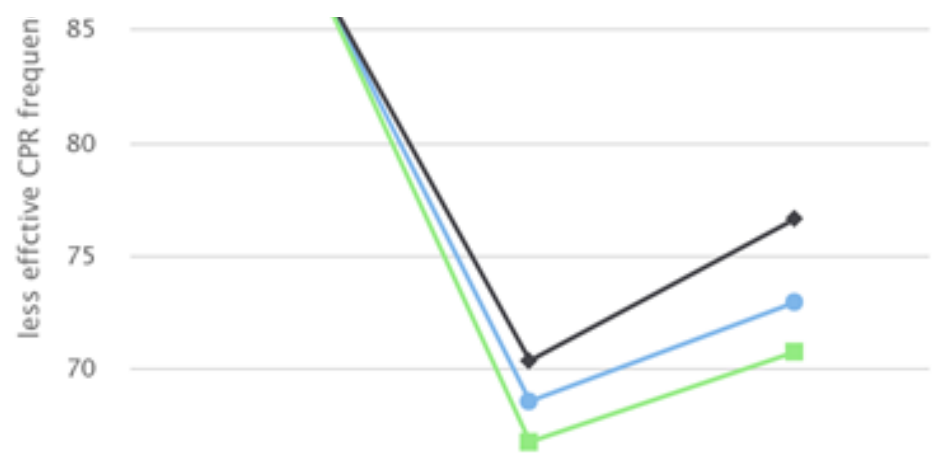

- General population

- S-CPR group

- CC-CPR group

65

TO

Effective CPR by group

Assessment by CPR-PES

20

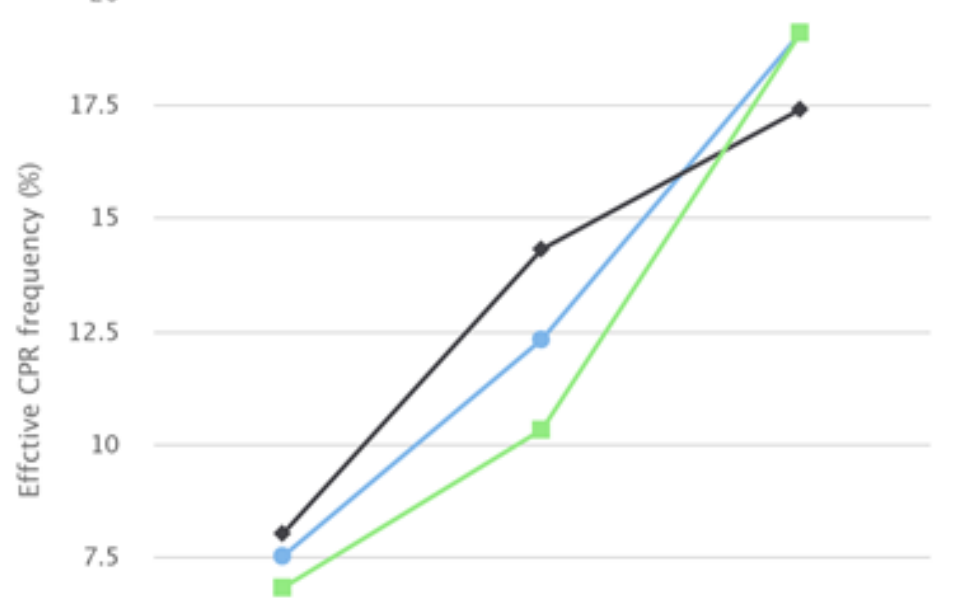

5

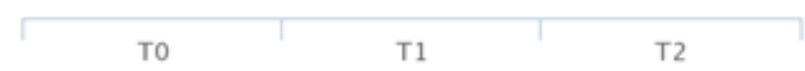

Highly effective CPR by group

Assessment by CPR-PES

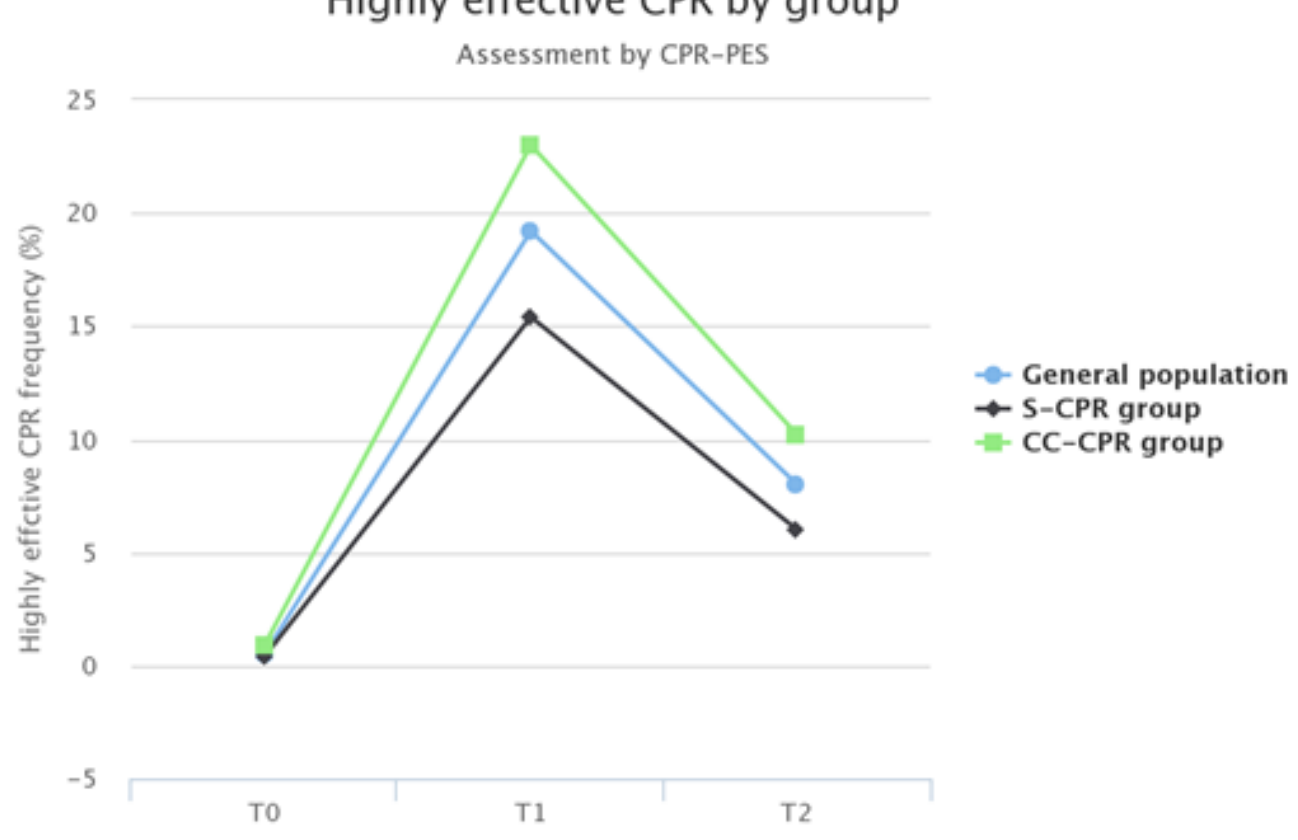

- General population

$\rightarrow$ S-CPR group

- CC-CPR group 
Pascal Cassan, Daniel Meyran

French Red Cross, First Aid and Emergency Department, Paris, France

Josephine Escutnaire, Evgeniya Babykina, Herve Hubert

Public Health Department EA 2694, University of Lille, Lille, France

Jacques Mansourati

Department of Cardiology, University Hospital of Brest and EA 4324 ORPHY, University of Western Brittany, Brest, France

Jacques Mansourati, Celine Dos Santos

Fédération Française de Cardiologie, Paris, France

Etienne Aliot

Department of Cardiology, University Hospital of Nancy, Nancy, France

Hervé Hubert

Department of Public Health EA2694

Institute of Health Engineering of Lille, University of Lille

42, rue Ambroise Paré

59120 Loos, France

Phone: +33 320623741

Fax: +33320623738

E-mail: herve.hubert@registreac.org

Article printed from Signa Vitae: http://www.signavitae.com

URL to article: http://www.signavitae.com/2016/o5/does-basiclife-support-training-simplification-foster-retention-of-lifesaving-maneuvers/

Copyright (C) 2015 Signa Vitae. All rights reserved. 